Research Article

\title{
Irregularity of Block Shift Networks and Hierarchical Hypercube Networks
}

\author{
Juanyan Fang, ${ }^{1}$ Iftikhar Ahmed ${ }^{10},{ }^{2,3}$ Abid Mehboob, ${ }^{4}$ Kashif Nazar, ${ }^{2}$ \\ and Haseeb Ahmad $\mathbb{D D}^{2,5}$ \\ ${ }^{1}$ Institute of Information Technology \& Engineering Management, Tongling College, Tongling 244000, China \\ ${ }^{2}$ Department of Mathematics, COMSATS University Islamabad, Lahore 54000, Pakistan \\ ${ }^{3}$ Department of Mathematics, Riphah International University, Lahore 54000, Pakistan \\ ${ }^{4}$ Department of Mathematics, Division of Science and Technology, University of Education, Lahore, Pakistan \\ ${ }^{5}$ Department of Mathematics, Lahore Leads University, Lahore, Pakistan
}

Correspondence should be addressed to Iftikhar Ahmed; iffi6301@gmail.com

Received 20 October 2019; Accepted 21 November 2019; Published 18 December 2019

Guest Editor: Jia-Bao Liu

Copyright (c) 2019 Juanyan Fang et al. This is an open access article distributed under the Creative Commons Attribution License, which permits unrestricted use, distribution, and reproduction in any medium, provided the original work is properly cited.

\begin{abstract}
There is extremely a great deal of mathematics associated with electrical and electronic engineering. It relies upon what zone of electrical and electronic engineering; for instance, there is much increasingly theoretical mathematics in communication theory, signal processing and networking, and so forth. Systems include hubs speaking with one another. A great deal of PCs connected together structure a system. Mobile phone clients structure a network. Networking includes the investigation of the most ideal method for executing a system. Graph theory has discovered a significant use in this zone of research. In this paper, we stretch out this examination to interconnection systems. Hierarchical interconnection systems (HINs) give a system to planning systems with diminished connection cost by exploiting the area of correspondence that exists in parallel applications. HINs utilize numerous levels. Lower-level systems give nearby correspondence, while more significant level systems encourage remote correspondence. HINs provide issue resilience within the sight of some defective nodes and additionally interfaces. Existing HINs can be comprehensively characterized into two classes: those that use nodes or potential interface replication and those that utilize reserve interface nodes.
\end{abstract}

\section{Introduction}

Graph theory has many applications in chemistry, physics, computer sciences, and other applied sciences [1-9]. Multiprocessor interconnection networks (MINs) are required to connect processor-memory pairs, each of which is known as the processing node. Design and usage of MINs have gained remarkable attention because of the availability of powerful microprocessors and memory chips and also due to its low cost $[10,11]$. Hierarchical interconnection network (HIN) [12] is a framework for designing new networks that decrease link cost and has applications in parallel communications. The multistage networks have applications as communication networks for parallel computing [12-14]. For details about graph theory, we recommend the references [15-19].
Throughout this article, all graphs are finite, undirected, and simple. Let $G=(V(G), E(G))$ be such a graph with vertex set $V(G)$ and edge set $E(G)$. The order of $G$ is the cardinality of its vertex set, and size is the cardinality of its edge set. In a network, the vertices of $G$ correspond to node, and an edge between two vertices is the link between these vertices. The degree of a vertex $u$ of a graph $G$ is symbolized by $d_{u}$ and is defined as the number of edges incident with $u$. A graph is said to be regular, if all its vertices have the same degree; otherwise, it is irregular.

For the first time in history, Chartrand et al. [20] underlined the study of irregular graphs. From that point forward, the irregularity degree and irregular graphs have turned into the essential open issue of graph theory. A graph is said to be a perfect graph if all the vertices have different 
degrees (i.e., no two vertices have the same degree). The fact no graph is perfect is proved in [21]. The graphs lying in the middle are called semiperfect (quasiperfect) graphs, in which each, aside from the two vertices, has various degrees [22]. The irregularity indices give the best knowledge about the irregularity of graph and have been studied extensively in the literature $[23,24]$. The primary irregularity index was presented in [25]. The Albertson index, $\mathrm{AL}(G)$, was introduced by Albertson in [26] as follows:

$$
\operatorname{AL}(G)=\sum_{u v \in E(G)}\left|d_{u}-d_{v}\right| .
$$

The irregularity indexes IRL (G) and IRLU (G) are defined by Vukičević and Graovac [27] as follows:

$$
\begin{gathered}
\operatorname{IRL}(G)=\sum_{u v \in E(G)}\left|\ln \left(d_{u}\right)-\ln \left(d_{v}\right)\right|, \\
\operatorname{IRLU}(G)=\sum_{u v \in E(G)} \frac{\left|\left(d_{u}\right)-\left(d_{v}\right)\right|}{\min \left(d_{u}, d_{v}\right)} .
\end{gathered}
$$

Recently, Abdo and Dimitrov [28] established the new idea of "total irregularity measure of a graph $G$," which was lately discussed in $[29,30]$. The Randić index itself is directly associated with an irregularity determination [31] as follows:

$$
\operatorname{IRA}(G)=\sum_{u v \in E(G)}\left(d_{u}^{-1 / 2}-d_{v}^{-1 / 2}\right)^{2} .
$$

Further irregularity indices of comparative nature can be followed in [30] in detail, and for the applications of indices in chemistry, we refer [31-42]. In [43], irregularity indices of nanotubes were determined. Gao et al. [44] computed irregularity measures of some dendrimers, and the same was computed for different molecular structures in [45]. In [46], irregularity measures for some classes of benzenoid systems were computed.

Irregularity indices investigated in this paper are given in Table 1. For the undefined notion in Table 1, we refer [47-52]. All of them belong to the family of degree-based irregularity indices.

\section{Methodology}

Let $G=(V(G), E(G))$ be such a graph with vertex set $V(G)$ and edge set $E(G)$. We use edge partition to find irregularity indices, and edge partition depends on the degree of end vertices of edges. Edges are partitioned by the same and different degrees of vertices hold edges.

2.1. Results for Block Shift Network (BSN). The block shift network can be denoted by BSN and was firstly introduced in 1991 by Pan and Chuang [53]. These are interconnection networks, and due to its hypercube topology, it has many benefits. The idea to design this network is to have a linkage in certain dimensions in order to make it a comparable performance and reduce number of links. The topology of BSN fulfils the requirements of the communication algorithms. BSN surpasses the hypercube in several respects while retaining most of its advantages, especially when the traffic has the locality property [54]. Many existing networks can be considered as special cases of BSN. For example, BSN - 1 is the shuffle-exchange network with $n$-dimensional hypercube, while BSN - 2 is the complete network, as shown in Figures 1 and 2, respectively. Let $G$ be a block shift network. It can be seen from Figure 1 that the number of vertices and edges in BSN -1 are $16 a^{2}$ and $24 a^{2}-2$, respectively. From Figure 2, one can observe that the number of vertices and edges in BSN -2 are $16 a^{2}$ and $32 a^{2}-2$, respectively.

Theorem 1. For the block shift network $B S N-1$, we have

(1) $\operatorname{VAR}(B S N-1)=\left(4 a^{2}-1 / 16 a^{4}\right)$

(2) $A L(B S N-1)=8$

(3) $\operatorname{IR} 1(B S N-1)=\left(5\left(4 a^{2}-1\right) / a^{2}\right)$

(4) $\operatorname{IR2}(B S N-1)=\sqrt{6} \sqrt{\left(216 a^{2}-42 / 6\left(24 a^{2}-2\right)\right)}-$ $\left(48 a^{2}-4 / 16 a^{2}\right)$

(5) $\operatorname{IRF}(B S N-1)=8$

(6) $\operatorname{IRFW}(B S N-1)=\left(4 / 108 a^{2}-21\right)$

(7) $\operatorname{IRA}(B S N-1)=(1213215869760357 /$ 9007199254740992)

(8) $\operatorname{IRB}(B S N-1)=(909911902320267 /$ $1125899906842624)$

(9) $\operatorname{IRC}(B S N-1)=-\left(36 a^{2}-16 \sqrt{6} a^{2}+1 / 4 a^{2}\right.$ $\left.\left(12 a^{2}-1\right)\right)$

(10) $\operatorname{IRDIF}(B S N-1)=(20 / 3)$

(11) $\operatorname{IRL}(B S N-1)=(3652105019575333 /$ $1125899906842624)$

(12) $\operatorname{IRLU}(B S N-1)=4$

(13) $\operatorname{IRLF}(B S N-1)=(4 \sqrt{6} / 3)$

(14) $\operatorname{IRLA}(B S N-1)=(16 / 5)$

(15) $\operatorname{IRD} 1(B S N-1)=(6243314768165359 /$ $1125899906842624)$

(16) $\operatorname{IRGA}(B S N-1)=(2941534708959071 /$ $18014398509481984)$

Proof. The order of graph is $n=|V(\mathrm{BSN}-1)|=16 a^{2}$, and its size is $m=|E(\mathrm{BSN}-1)|=24 a^{2}-2$. The vertex set of BSN -1 can be divided into the following classes by means of degrees:

$$
\begin{aligned}
& V_{1}(\mathrm{BSN}-1)=\left\{v \in V(\mathrm{BSN}-1): d_{u}=2\right\}, \\
& V_{2}(\mathrm{BSN}-1)=\left\{v \in V(\mathrm{BSN}-1): d_{u}=3\right\} .
\end{aligned}
$$

The edge set of BSN - 1 can be divided into the following classes with respect to the degrees of end vertices:

$$
\begin{aligned}
& E_{1}(\mathrm{BSN}-1)=\left\{u v \in E(\mathrm{BSN}-1): d_{u}=d_{v}=3\right\}, \\
& E_{2}(\mathrm{BSN}-1)=\left\{u v \in E(\mathrm{BSN}-1): d_{u}=2, d_{v}=3\right\} .
\end{aligned}
$$

And the cardinality of edges is as follows: 
TABLE 1: Irregularity indices.

\begin{tabular}{lr}
\hline $\operatorname{VAR}(G)=\left(M_{1}(G) / n\right)-\left((2 m / n)^{2}\right)$ & $\operatorname{IRC}(G)=(\operatorname{RR}(G) / m)-(2 m / n)$ \\
$\operatorname{AL}(G)=\sum_{u v \in E(G)}\left|d_{u}-d_{v}\right|$ & $\operatorname{IRDIF}(G)=\sum_{u v \in E(G)}\left|\left(d_{u} / d_{v}\right)-\left(d_{v} / d_{u}\right)\right|$ \\
$\operatorname{IR} 1(G)=F(G)-(2 m / n) M_{1}(G)$ & $\operatorname{IRL}(G)=\sum_{u v \in E(G)}\left|\ln \left(d_{u}\right)-\ln \left(d_{v}\right)\right|$ \\
$\operatorname{IR2}(G)=\sqrt{\left(M_{2}(G) / m\right)}-(2 m / n)$ & $\operatorname{IRLU}(G)=\sum_{u v \in E(G)}\left(\left|\left(d_{u}\right)-\left(d_{v}\right)\right| / \min \left(d_{u}, d_{v}\right)\right)$ \\
$\operatorname{IRF}(G)=F(G)-2 M_{2}(G)$ & $\operatorname{IRLF}(G)=\sum_{u v \in E(G)}\left(\left|d_{u}-d_{v}\right| / \sqrt{\left(d_{u} \times d_{v}\right)}\right)$ \\
$\operatorname{IRFW}(G)=\left(\operatorname{IRF}(G) / M_{2}(G)\right)$ & $\operatorname{IRLA}(G)=\sum_{u v \in E(G)} 2\left(\left|d_{u}-d_{v}\right| / d_{u}+d_{v}\right)$ \\
$\operatorname{IRA}(G)=\sum_{u v \in E(G)}\left(d_{u}^{-1 / 2}-d_{v}^{-1 / 2}\right)^{2}$ & $\operatorname{IRD} 1(G)=\sum_{u v \in E(G)} \ln \left[1+\left|d_{u}-d_{v}\right|\right]$ \\
$\operatorname{IRB}(G)=\sum_{u v \in E(G)}\left(d_{u}^{1 / 2}-d_{v}^{1 / 2}\right)^{2}$ & $\operatorname{IRGA}(G)=\sum_{u v \in E(G)} \ln \left(d_{u}+d_{v} / 2 \sqrt{\left(d_{u} \times d_{v}\right)}\right)$ \\
\hline
\end{tabular}

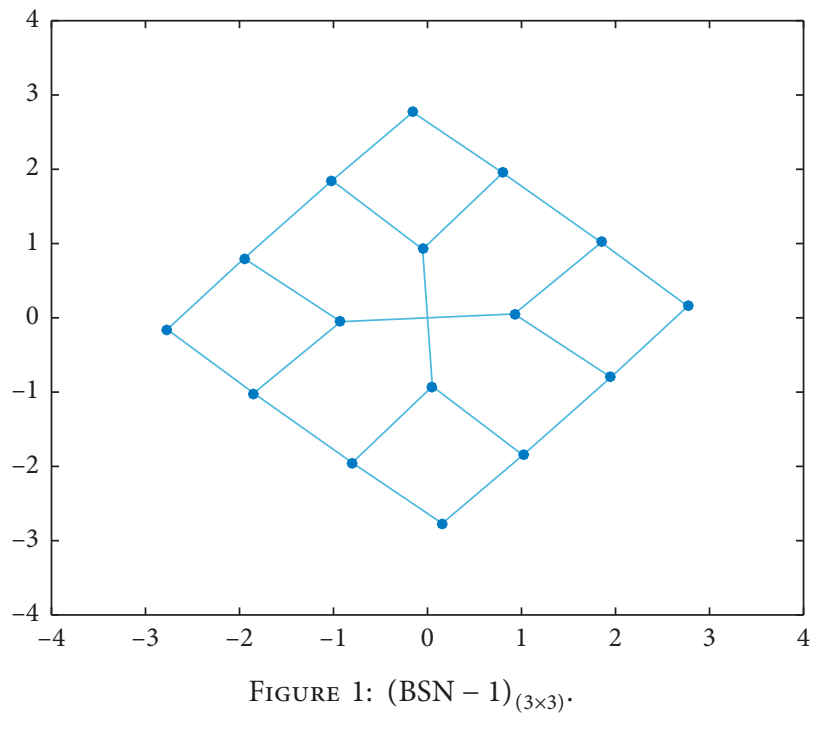

First, we find some topological indices, which will be used in irregularity indices:

$$
\begin{aligned}
M_{1}(\mathrm{BSN}-1) & =144 a^{2}-20, \\
M_{2}(\mathrm{BSN}-1) & =216 a^{2}-42, \\
F(\mathrm{BSN}-1) & =432 a^{2}-76, \\
\operatorname{RR}(\mathrm{BSN}-1) & =72 a^{2}+8 \sqrt{6}-30 .
\end{aligned}
$$

Now, by definitions given in Table 1 , we have

$$
\begin{aligned}
\operatorname{VAR}(\mathrm{BSN}-1) & =\frac{M_{1}(\mathrm{BSN}-1)}{n}-\left(\frac{2 m}{n}\right)^{2} \\
& =\frac{144 a^{2}-20}{16 a^{2}}-\left(\frac{224 a^{2}-2}{16 a^{2}}\right)^{2} \\
& =\frac{4 a^{2}-1}{16 a^{4}} .
\end{aligned}
$$

$$
\begin{aligned}
\operatorname{AL}(\mathrm{BSN}-1) & =\sum_{u v \in E(\mathrm{BSN}-1)}\left|d_{u}-d_{v}\right| \\
& =\sum_{u v \in E_{1}(\mathrm{BSN}-1)}(0)+\sum_{u v \in E_{2}(\mathrm{BSN}-1)}|(2)-(3)| \\
& =8 .
\end{aligned}
$$

$$
\begin{aligned}
\operatorname{IR} 1(\mathrm{BSN}-1) & =F(\mathrm{BSN}-1)-\frac{2 m}{n} M_{1}(\mathrm{BSN}-1) \\
& =432 a^{2}-76-\frac{2\left(24 a^{2}-2\right)}{16 a^{2}} 144 a^{2}-20 \\
& =\frac{5\left(4 a^{2}-1\right)}{a^{2}} .
\end{aligned}
$$

$$
\begin{aligned}
\operatorname{IR} 2(\mathrm{BSN}-1) & =\sqrt{\frac{M_{2}(\mathrm{BSN}-1)}{m}}-\frac{2 m}{n} \\
& =\sqrt{\frac{216 a^{2}-42}{24 a^{2}-2}}-\frac{2\left(24 a^{2}-2\right)}{16 a^{2}}
\end{aligned}
$$$$
\left|E_{1}(\mathrm{BSN}-1)\right|=24 a^{2}-10,
$$$$
\left|E_{2}(\mathrm{BSN}-1)\right|=8 \text {. }
$$ 


$$
\begin{aligned}
\operatorname{IRF}(\mathrm{BSN}-1) & =F(\mathrm{BSN}-1)-2 M_{2}(\mathrm{BSN}-1) \\
& =432 a^{2}-76-2\left(216 a^{2}-42\right) \\
& =8
\end{aligned}
$$

$$
\begin{aligned}
\operatorname{IRFW}(\mathrm{BSN}-1) & =\frac{\operatorname{IRF}(\mathrm{BSN}-1)}{M_{2}(\mathrm{BSN}-1)} \\
& =\frac{8}{216 a^{2}-42} \\
& =8 .
\end{aligned}
$$

$$
\begin{aligned}
\operatorname{IRA}(\mathrm{BSN}-1)= & \sum_{u v \in E(\mathrm{BSN}-1)}\left(d_{u}^{-1 / 2}-d_{v}^{-1 / 2}\right)^{2} \\
= & \sum_{u v \in E_{1}(\mathrm{BSN}-1)}(0) \\
& +\sum_{\substack{u v \in E_{2}(\mathrm{BSN}-1) \\
=}}\left((2)^{-1 / 2}-(3)^{-1 / 2}\right)^{2} \\
& \frac{1213215869760357}{9007199254740992} .
\end{aligned}
$$$$
\operatorname{IRB}(\mathrm{BSN}-1)=\sum_{u v \in E(\mathrm{BSN}-1)}\left(d_{u}^{1 / 2}-d_{v}^{1 / 2}\right)^{2}
$$$$
=\sum_{u v \in E_{1}(\mathrm{BSN}-1)}(0)
$$$$
+\sum_{u v \in E_{2}(\mathrm{BSN}-1)}\left((2)^{1 / 2}-(3)^{1 / 2}\right)^{2}
$$$$
=\frac{909911902320267}{1125899906842624} \text {. }
$$$$
\operatorname{IRC}(\mathrm{BSN}-1)=\frac{\mathrm{RR}(\mathrm{BSN}-1)}{m}-\frac{2 m}{n}
$$$$
=\frac{72 a^{2}+8 \sqrt{6}-30}{24 a^{2}-2}-\frac{2\left(24 a^{2}-2\right)}{16 a^{2}}
$$$$
=-\frac{36 a^{2}-16 \sqrt{6} a^{2}+1}{4 a^{2}\left(12 a^{2}-1\right)} \text {. }
$$

$$
\begin{aligned}
\operatorname{IRDIF}(\mathrm{BSN}-1) & =\sum_{u v \in E(\mathrm{BSN}-1)}\left|\frac{d_{u}}{d_{v}}-\frac{d_{v}}{d_{u}}\right| \\
& =\sum_{u v \in E_{1}(\mathrm{BSN}-1)}(0)+\sum_{u v \in E_{2}(\mathrm{BSN}-1)}\left|\frac{2}{3}-\frac{3}{2}\right| \\
& =\frac{20}{3} .
\end{aligned}
$$

$$
\begin{aligned}
\operatorname{IRL}(\mathrm{BSN}-1)= & \sum_{u v \in E(\mathrm{BSN}-1)}\left|\ln \left(d_{u}\right)-\ln \left(d_{v}\right)\right| \\
= & \sum_{u v \in E_{1}(\mathrm{BSN}-1)}(0) \\
& +\sum_{u v \in E_{2}(\mathrm{BSN}-1)}|\ln (2)-\ln (3)| \\
= & \frac{3652105019575333}{1125899906842624} .
\end{aligned}
$$

$$
\begin{aligned}
\operatorname{IRLU}(\mathrm{BSN}-1) & =\sum_{u v \in E(\mathrm{BSN}-1)} \frac{\left|\left(d_{u}\right)-\left(d_{v}\right)\right|}{\min \left(d_{u}, d_{v}\right)} \\
& =\sum_{u v \in E_{1}(\mathrm{BSN}-1)}(0)+\sum_{u v \in E_{2}(\mathrm{BSN}-1)} \frac{|(2)-(3)|}{\min (2,3)} \\
& =4 .
\end{aligned}
$$

$$
\begin{aligned}
\operatorname{IRLA}(\mathrm{BSN}-1) & =\sum_{u v \in E(\mathrm{BSN}-1)} 2 \frac{\left|d_{u}-d_{v}\right|}{d_{u}+d_{v}} \\
& =\sum_{u v \in E_{1}(\mathrm{BSN}-1)}(0)+\sum_{u v \in E_{2}(\mathrm{BSN}-1)} 2 \frac{|2-3|}{2+3} \\
& =\frac{16}{5} .
\end{aligned}
$$

$$
\begin{aligned}
\operatorname{IRLF}(\mathrm{BSN}-1) & =\sum_{u v \in E(\mathrm{BSN}-1)} \frac{\left|d_{u}-d_{v}\right|}{\sqrt{\left(d_{u} \times d_{v}\right)}} \\
& =\sum_{u v \in E_{1}(\mathrm{BSN}-1)}(0)+\sum_{u v \in E_{2}(\mathrm{BSN}-1)} \frac{|2-3|}{\sqrt{(2 \times 3)}} \\
& =\frac{4 \sqrt{6}}{3} .
\end{aligned}
$$

$$
\begin{aligned}
\operatorname{IRD} 1(\mathrm{BSN}-1)= & \sum_{u v \in E(\mathrm{BSN}-1)} \ln \left[1+\left|d_{u}-d_{v}\right|\right] \\
= & \sum_{u v \in E_{1}(\mathrm{BSN}-1)}(0) \\
& +\sum_{u v \in E_{2}(\mathrm{BSN}-1)} \ln [1+|(2)-(3)|] \\
= & \frac{6243314768165359}{1125899906842624} .
\end{aligned}
$$

$$
\begin{aligned}
\operatorname{IRGA}(\mathrm{BSN}-1)= & \sum_{u v \in E(\mathrm{BSN}-1)} \ln \left(\frac{d_{u}+d_{v}}{2 \sqrt{\left(d_{u} \times d_{v}\right)}}\right) \\
= & \sum_{u v \in E_{1}(\mathrm{BSN}-1)}(0) \\
& +\sum_{u v \in E_{2}(\mathrm{BSN}-1)} \ln \left(\frac{2+3}{2 \sqrt{(2 \times 3)}}\right) \\
= & \frac{2941534708959071}{18014398509481984} .
\end{aligned}
$$

Theorem 2. For the block shift network BSN-2, we have

(1) $\operatorname{VAR}(B S N-2)=\left(4 a^{2}-1 / 16 a^{4}\right)$

(2) $A L(B S N-2)=12$

(3) $\operatorname{IR} 1(B S N-2)=\left(7\left(4 a^{2}-1\right) / a^{2}\right)$ 
(4) $\operatorname{IR} 2(B S N-2)=4 \sqrt{\left(512 a^{2}-80 / 16\left(32 a^{2}-2\right)\right)}-$ $\left(64 a^{2}-4 / 16 a^{2}\right)$

(5) $\operatorname{IRF}(B S N-2)=12$

(6) $\operatorname{IRFW}(B S N-2)=\left(3 / 128 a^{2}-20\right)$

(7) $\operatorname{IRA}(B S N-2)=(20694009944167803 /$ $288230376151711744)$

(8) $\operatorname{IRB}(B S N-2)=(15520507458125877 /$ 18014398509481984)

(9) $\operatorname{IRC}(B S N-2)=-\left(\left(80 a^{2}-48 \sqrt{3} a^{2}+1\right) /\right.$ $\left.\left(4 a^{2}\left(16 a^{2}-1\right)\right)\right)$

(10) $\operatorname{IRDIF}(B S N-2)=7$

(11) $\operatorname{IRL}(B S N-2)=(3886814622885039 /$ $1125899906842624)$

(12) $\operatorname{IRLU}(B S N-2)=4$

(13) $\operatorname{IRLF}(B S N-2)=2 \sqrt{3}$

(14) $\operatorname{IRLA}(B S N-2)=(24 / 7)$

(15) $I R D 1(B S N-2)=(18729944304496077 /$ 2251799813685248)

(16) $I R G A(B S N-2)=(2228664339909267 /$ $18014398509481984)$

Proof. The order of graph is $n=|V(\mathrm{BSN}-2)|=16 a^{2}$, and its size is $m=|E(\mathrm{BSN}-2)|=32 a^{2}-2$. The vertex set of BSN -2 can be divided into the following classes by means of degrees:

$$
\begin{aligned}
& V_{1}(\mathrm{BSN}-2)=\left\{v \in V(\mathrm{BSN}-2): d_{u}=3\right\}, \\
& V_{2}(\mathrm{BSN}-2)=\left\{v \in V(\mathrm{BSN}-2): d_{u}=4\right\} .
\end{aligned}
$$

The edge set of BSN -2 can be divided into the following classes with respect to the degrees of end vertices:

$$
\begin{aligned}
& E_{1}(\mathrm{BSN}-2)=\left\{u v \in E(\mathrm{BSN}-2): d_{u}=d_{v}=4\right\}, \\
& E_{2}(\mathrm{BSN}-2)=\left\{u v \in E(\mathrm{BSN}-2): d_{u}=3, d_{v}=4\right\} .
\end{aligned}
$$

And the cardinality of edges is as follows:

$$
\begin{aligned}
& \left|E_{1}(\mathrm{BSN}-2)\right|=32 a^{2}-14, \\
& \left|E_{2}(\mathrm{BSN}-2)\right|=12 .
\end{aligned}
$$

First, we find some topological indices, which will be used in irregularity indices:

$$
\begin{aligned}
M_{1}(\mathrm{BSN}-2) & =256 a^{2}-28, \\
M 2(\mathrm{BSN}-2) & =512 a^{2}-80, \\
F(\mathrm{BSN}-2) & =1024 a^{2}-148, \\
\operatorname{RR}(\mathrm{BSN}-2) & =128 a^{2}+24 \sqrt{3}-56 .
\end{aligned}
$$

Now, from the definitions given in Table 1, we have

$$
\begin{aligned}
\operatorname{VAR}(\mathrm{BSN}-2) & =\frac{M_{1}(\mathrm{BSN}-2)}{n}-\left(\frac{2 m}{n}\right)^{2} \\
& =\frac{256 a^{2}-28}{16 a^{2}}-\left(\frac{232 a^{2}-2}{16 a^{2}}\right)^{2} \\
& =\frac{4 a^{2}-1}{16 a^{4}} . \\
\operatorname{AL}(\mathrm{BSN}-2) & =\sum_{u v \in E(\mathrm{BSN}-2)}\left|d_{u}-d_{v}\right| \\
& =\sum_{u v \in E_{1}(\mathrm{BSN}-2)}(0)+\sum_{u v \in E_{2}(\mathrm{BSN}-2)}|(3)-(4)| \\
& =12 . \\
\operatorname{IR} 1(\mathrm{BSN}-2) & =F(\mathrm{BSN}-2)-\frac{2 m}{n} M_{1}(\mathrm{BSN}-2) \\
& =1024 a^{2}-148-\frac{2\left(32 a^{2}-2\right)}{16 a^{2}} 256 a^{2}-28 \\
& =\frac{7\left(4 a^{2}-1\right)}{a^{2}} .
\end{aligned}
$$

$$
\begin{aligned}
\operatorname{IR} 2(\mathrm{BSN}-2) & =\sqrt{\frac{M_{2}(\mathrm{BSN}-2)}{m}}-\frac{2 m}{n} \\
& =\sqrt{\frac{512 a^{2}-80}{32 a^{2}-2}-\frac{2\left(32 a^{2}-2\right)}{16 a^{2}}} \\
& =4 \sqrt{\frac{512 a^{2}-80}{16\left(32 a^{2}-2\right)}}-\frac{64 a^{2}-4}{16 a^{2}} .
\end{aligned}
$$

$$
\begin{aligned}
\operatorname{IRF}(\mathrm{BSN}-2) & =F(\mathrm{BSN}-2)-2 M_{2}(\mathrm{BSN}-2) \\
& =1024 a^{2}-148-2\left(512 a^{2}-80\right) \\
& =12 .
\end{aligned}
$$

$$
\begin{aligned}
\operatorname{IRFW}(\mathrm{BSN}-2) & =\frac{\operatorname{IRF}(\mathrm{BSN}-2)}{M_{2}(\mathrm{BSN}-2)} \\
& =\frac{12}{512 a^{2}-80} \\
& =12 .
\end{aligned}
$$

$$
\begin{aligned}
\operatorname{IRA}(\mathrm{BSN}-2)= & \sum_{u v \in E(\mathrm{BSN}-2)}\left(d_{u}^{-1 / 2}-d_{v}^{-1 / 2}\right)^{2} \\
= & \sum_{u v \in E_{1}(\mathrm{BSN}-2)}(0) \\
& +\sum_{u v \in E_{2}(\mathrm{BSN}-2)}\left((3)^{-1 / 2}-(4)^{-1 / 2}\right)^{2} \\
= & \frac{20694009944167803}{288230376151711744} .
\end{aligned}
$$




$$
\begin{aligned}
\operatorname{IRB}(\mathrm{BSN}-2)= & \sum_{u v \in E(\mathrm{BSN}-2)}\left(d_{u}^{1 / 2}-d_{v}^{1 / 2}\right)^{2} \\
= & \sum_{u v \in E_{1}(\mathrm{BSN}-2)}(0) \\
& +\sum_{u v \in E_{2}(\mathrm{BSN}-2)}\left((3)^{1 / 2}-(4)^{1 / 2}\right)^{2} \\
= & \frac{15520507458125877}{18014398509481984} . \\
\operatorname{IRC}(\mathrm{BSN}-2)= & \frac{\operatorname{RR}(\mathrm{BSN}-2)}{m}-\frac{2 m}{n} \\
= & \frac{128 a^{2}+24 \sqrt{3}-56}{32 a^{2}-2}-\frac{2\left(32 a^{2}-2\right)}{16 a^{2}} \\
= & -\frac{80 a^{2}-48 \sqrt{3} a^{2}+1}{4 a^{2}\left(16 a^{2}-1\right)} .
\end{aligned}
$$$$
\begin{aligned}
\operatorname{IRDIF}(\mathrm{BSN}-2)= & \sum_{u v \in E(\mathrm{BSN}-2)}\left|\frac{d_{u}}{d_{v}}-\frac{d_{v}}{d_{u}}\right| \\
= & \sum_{u v \in E_{1}(\mathrm{BSN}-2)}(0) \\
& +\sum_{u v \in E_{2}(\mathrm{BSN}-2)}\left|\frac{3}{4}-\frac{4}{3}\right|
\end{aligned}
$$$$
=7 \text {. }
$$

$$
\begin{aligned}
\operatorname{IRL}(\mathrm{BSN}-2)= & \sum_{u v \in E(\mathrm{BSN}-2)}\left|\ln \left(d_{u}\right)-\ln \left(d_{v}\right)\right| \\
= & \sum_{u v \in E_{1}(\mathrm{BSN}-2)}(0) \\
& +\sum_{u v \in E_{2}(\mathrm{BSN}-2)}|\ln (3)-\ln (4)| \\
= & \frac{3886814622885039}{1125899906842624} .
\end{aligned}
$$

$$
\begin{aligned}
\operatorname{IRLU}(\mathrm{BSN}-2) & =\sum_{u v \in E(\mathrm{BSN}-2)} \frac{\left|\left(d_{u}\right)-\left(d_{v}\right)\right|}{\min \left(d_{u}, d_{v}\right)} \\
& =\sum_{u v \in E_{1}(\mathrm{BSN}-2)}(0)+\sum_{u v \in E_{2}(\mathrm{BSN}-2)} \frac{|(3)-(4)|}{\min (3,4)} \\
& =4 .
\end{aligned}
$$

$$
\begin{aligned}
\operatorname{IRLF}(\mathrm{BSN}-2) & =\sum_{u v \in E(\mathrm{BSN}-2)} \frac{\left|d_{u}-d_{v}\right|}{\sqrt{\left(d_{u} \times d_{v}\right)}} \\
& =\sum_{u v \in E_{1}(\mathrm{BSN}-2)}(0)+\sum_{u v \in E_{2}(\mathrm{BSN}-2)} \frac{|3-4|}{\sqrt{(3 \times 4)}} \\
& =2 \sqrt{3} .
\end{aligned}
$$

$$
\begin{aligned}
& \operatorname{IRLA}(\mathrm{BSN}-2)=\sum_{u v \in E(\mathrm{BSN}-2)} 2 \frac{\left|d_{u}-d_{v}\right|}{d_{u}+d_{v}} \\
& =\sum_{u v \in E_{1}(\mathrm{BSN}-2)}(0)+\sum_{u v \in E_{2}(\mathrm{BSN}-2)} 2 \frac{|3-4|}{3+4} \\
& =\frac{24}{7} \text {. } \\
& \operatorname{IRD} 1(\mathrm{BSN}-2)=\sum_{u v \in E(\mathrm{BSN}-2)} \ln \left[1+\left|d_{u}-d_{v}\right|\right] \\
& =\sum_{u v \in E_{1}(\mathrm{BSN}-2)}(0) \\
& +\sum_{u v \in E_{2}(\mathrm{BSN}-2)} \ln [1+|(3)-(4)|] \\
& =\frac{18729944304496077}{2251799813685248} \text {. } \\
& \operatorname{IRGA}(\mathrm{BSN}-2)=\sum_{u v \in E(\mathrm{BSN}-2)} \ln \left(\frac{d_{u}+d_{v}}{2 \sqrt{\left(d_{u} \times d_{v}\right)}}\right) \\
& =\sum_{u v \in E_{1}(\mathrm{BSN}-2)}(0) \\
& +\sum_{u v \in E_{2}(\mathrm{BSN}-2)} \ln \left(\frac{3+4}{2 \sqrt{(3 \times 4)}}\right) \\
& =\frac{2228664339909267}{18014398509481984} \text {. }
\end{aligned}
$$

2.2. Results for Hierarchical Hypercube Network (HHC). Hierarchical hypercube network (HHC) has many features, for example, symmetry and logarithmic diameter, which imply easy and fast algorithms for communication [55]. The structure of an $n$ - (HHC) consists of three levels of hierarchy. At the lowest level of hierarchy, there is a pool of $2 n$ nodes. These nodes are grouped into clusters of $2 m$ nodes each, and the nodes in each cluster are interconnected to form an $m-$ cube called the son cube or the $S$-cube. The set of the $S$-cubes constitutes the second level of hierarchy [56].

Due to the hierarchical structure, HHC has the advantages that are gained by hierarchy. "In addition, hierarchical structures are capable of exploiting the locality of reference (communication), and they are fault tolerant. Other attractive properties of the HHC structure are logarithmic diameter and a topology inherited from, and closely related to, the hypercube topology. The former property implies fast communication, and the latter implies easy mapping of operations from $\mathrm{HC}$ to $\mathrm{HHC}$. The $\mathrm{HHC}$ can emulate the hypercube for a large class of problems (divide conquer), without a significant increase in processing time. The HHC can embed rings and HHCs of lower dimension. In addition, $\mathrm{HHC}$ embeds the cube connected cycles (CCC) 
[57]." As a result, the performance of HHC is in the worst case equivalent to the performance of the CCC.

The number of vertices and edges in HHC -1 are $16 a+$ 16 and $24 a+20$, respectively. The number of vertices and edges in HHC -2 are $16 a+16$ and $32 a+28$, respectively. $\mathrm{HHC}-1$ and $\mathrm{HHC}-2$ are shown in Figures 3 and 4, respectively.

Theorem 3. For the hierarchical hypercube network $H H C-1$, we have

(1) $\operatorname{VAR}(H H C-1)=\left(2 a+1 / 4(a+1)^{2}\right)$
(2) $\operatorname{AL}(H H C-1)=16$
(3) $\operatorname{IR} 1(H H C-1)=(20(2 a+1) / a+1)$
(4) $\operatorname{IR} 2(H H C-1)=2 \sqrt{3} \sqrt{(18 a+11 / 24 a+20)}$
$-(6 a+5 / 2(a+1))$

(5) $\operatorname{IRF}(H H C-1)=16$

(6) $\operatorname{IRFW}(H H C-1)=(4 / 54 a+33)$

(7) $\operatorname{IRA}(H H C-1)=(1213215869760357 /$ 4503599627370496)

(8) $\operatorname{IRB}(H H C-1)=(909911902320267 /$ $562949953421312)$

(9) $\operatorname{IRC}(H H C-1)=(72 a+16 \sqrt{6}+12 / 24 a+20)$ $-(48 a+40 / 16 a+16)$

(10) $\operatorname{IRDIF}(H H C-1)=(40 / 3)$

(11) $\operatorname{IRL}(H H C-1)=(3652105019575333 /$ $562949953421312)$

(12) $\operatorname{IRLU}(H H C-1)=8$

(13) $\operatorname{IRLF}(H H C-1)=(8 \sqrt{6} / 3)$

(14) $\operatorname{IRLA}(H H C-1)=(32 / 5)$

(15) $\operatorname{IRD} 1(H H C-1)=(6243314768165359 /$ 562949953421312)

(16) $\operatorname{IRGA}(H H C-1)=(2941534708959071 /$ 9007199254740992)

Proof. The order of graph is $n=|V(\mathrm{HHC}-1)|=16 a+16$, and its size is $m=|E(\mathrm{HHC}-1)|=24 a+20$. The vertex set of $\mathrm{HHC}-1$ can be divided into the following classes by means of degrees:

$$
\begin{aligned}
& V_{1}(\mathrm{HHC}-1)=\left\{v \in V(\mathrm{HHC}-1): d_{u}=2\right\}, \\
& V_{2}(\mathrm{HHC}-1)=\left\{v \in V(\mathrm{HHC}-1): d_{u}=3\right\} .
\end{aligned}
$$

The edge set of HHC - 1 can be divided into the following classes with respect to the degrees of end vertices:

$E_{1}(\mathrm{HHC}-1)=\left\{u v \in E(\mathrm{HHC}-1): d_{u}=d_{v}=3\right\}$,

$E_{2}(\mathrm{HHC}-1)=\left\{u v \in E(\mathrm{HHC}-1): d_{u}=2, d_{v}=3\right\}$.

And the cardinality of edges is as follows:
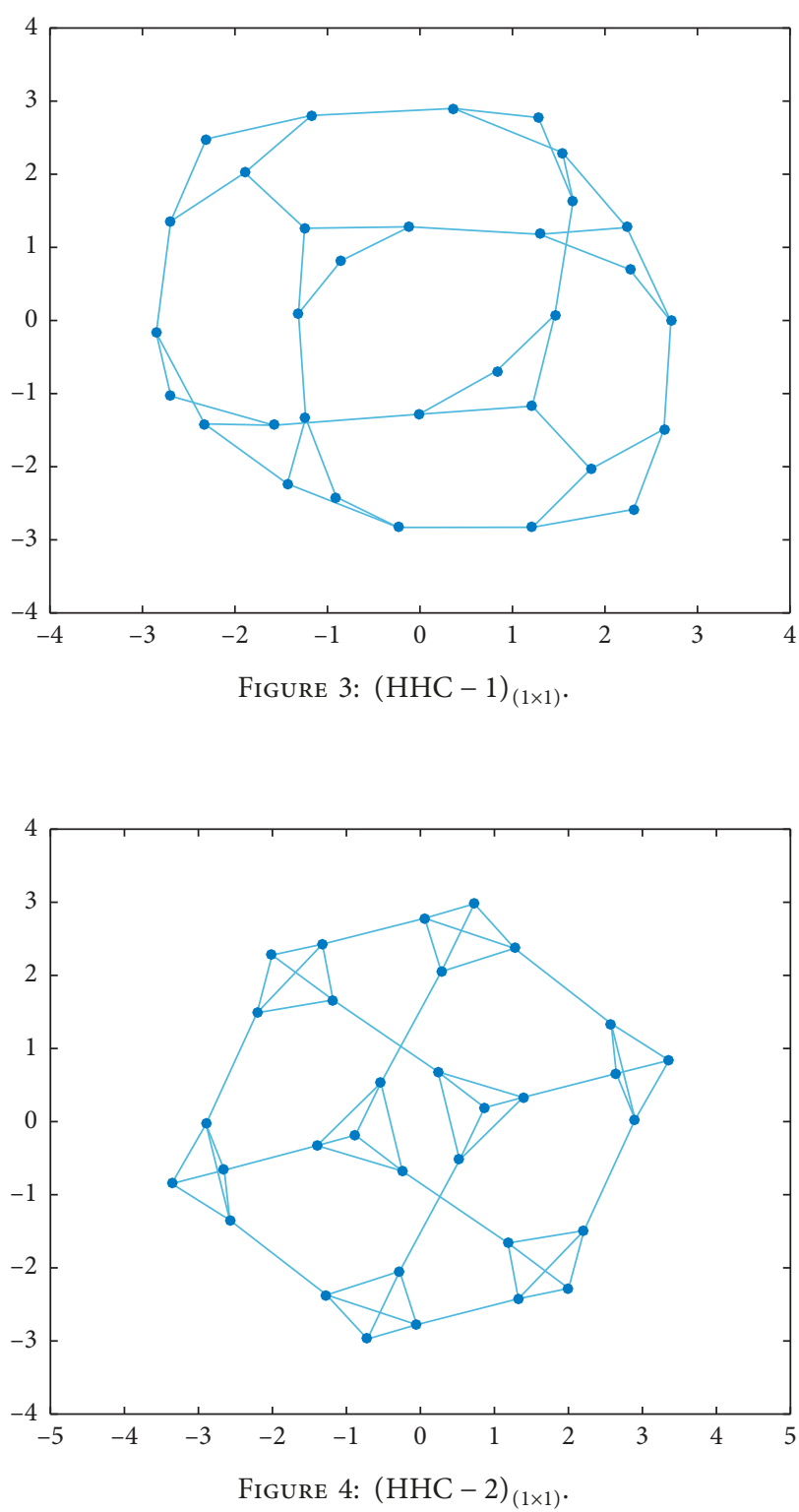

$$
\begin{aligned}
& \left|E_{1}(\mathrm{HHC}-1)\right|=24 a+4, \\
& \left|E_{2}(\mathrm{HHC}-1)\right|=16 .
\end{aligned}
$$

First, we find some topological indices, which will be used in irregularity indices:

$$
\begin{aligned}
M_{1}(\mathrm{HHC}-1) & =144 a+104, \\
M 2(\mathrm{HHC}-1) & =216 a+132, \\
F(\mathrm{HHC}-1) & =432 a+280, \\
\operatorname{RR}(\mathrm{HHC}-1) & =72 a+16 \sqrt{6}+12 .
\end{aligned}
$$

Now from definitions, we have 


$$
\begin{aligned}
\operatorname{VAR}(\mathrm{HHC}-1) & =\frac{M_{1}(\mathrm{HHC}-1)}{n}-\left(\frac{2 m}{n}\right)^{2} \\
& =\frac{144 a+104}{16 a+16}-\left(\frac{224 a+20}{16 a+16}\right)^{2} \\
& =\frac{2 a+1}{4(a+1)^{2}} . \\
\operatorname{AL}(\mathrm{HHC}-1) & =\sum_{u v \in E(\mathrm{HHC}-1)}\left|d_{u}-d_{v}\right| \\
& =\sum_{u v \in E_{1}(\mathrm{HHC}-1)}(0)+\sum_{u v \in E_{2}(\mathrm{HHC}-1)}|(2)-(3)| \\
& =16 .
\end{aligned}
$$

(49)

$$
\begin{aligned}
\operatorname{IR} 1(\mathrm{HHC}-1) & =F(\mathrm{HHC}-1)-\frac{2 m}{n} M_{1}(\mathrm{HHC}-1) \\
& =432 a+280-\frac{2(24 a+20)}{16 a+16} 144 a+104 \\
& =\frac{20(2 a+1)}{a+1} .
\end{aligned}
$$

$$
\begin{aligned}
\operatorname{IR} 2(\mathrm{HHC}-1) & =\sqrt{\frac{M_{2}(\mathrm{HHC}-1)}{m}}-\frac{2 m}{n} \\
& =\sqrt{\frac{216 a+132}{24 a+20}}-\frac{2(24 a+20)}{16 a+16} \\
& =2 \sqrt{3} \sqrt{\frac{18 a+11}{24 a+20}}-\frac{6 a+5}{2(a+1)}
\end{aligned}
$$

$\operatorname{IRF}(\mathrm{HHC}-1)=F(\mathrm{HHC}-1)-2 M_{2}(\mathrm{HHC}-1)$

$$
\begin{aligned}
& =432 a+280-2(216 a+132) \\
& =16 .
\end{aligned}
$$

$$
\begin{aligned}
\operatorname{IRFW}(\mathrm{HHC}-1) & =\frac{\operatorname{IRF}(\mathrm{HHC}-1)}{M_{2}(\mathrm{HHC}-1)} \\
& =\frac{16}{216 a+132} \\
& =16 .
\end{aligned}
$$

$$
\begin{aligned}
\operatorname{IRA}(\mathrm{HHC}-1)= & \sum_{u v \in E(\mathrm{HHC}-1)}\left(d_{u}^{-1 / 2}-d_{v}^{-1 / 2}\right)^{2} \\
= & \sum_{u v \in E_{1}(\mathrm{HHC}-1)}(0) \\
& +\sum_{u v \in E_{2}(\mathrm{HHC}-1)}\left((2)^{-1 / 2}-(3)^{-1 / 2}\right)^{2} \\
= & \frac{1213215869760357}{4503599627370496} .
\end{aligned}
$$

$$
\begin{aligned}
\operatorname{IRC}(\mathrm{HHC}-1) & =\frac{\mathrm{RR}(\mathrm{HHC}-1)}{m}-\frac{2 m}{n} \\
& =\frac{72 a+16 \sqrt{6}+12}{24 a+20}-\frac{2(24 a+20)}{16 a+16} \\
& =\frac{72 a+16 \sqrt{6}+12}{24 a+20}-\frac{48 a+40}{16 a+16} \\
\operatorname{IRDIF}(\mathrm{HHC}-1) & =\sum_{u v \in E(\mathrm{HHC}-1)}\left|\frac{d_{u}}{d_{v}}-\frac{d_{v}}{d_{u}}\right| \\
& =\sum_{u v \in E_{1}(\mathrm{HHC}-1)}(0)+\sum_{u v \in E_{2}(\mathrm{HHC}-1)}\left|\frac{2}{3}-\frac{3}{2}\right| \\
& =\frac{40}{3} .
\end{aligned}
$$

$$
\begin{aligned}
\operatorname{IRL}(\mathrm{HHC}-1)= & \sum_{u v \in E(\mathrm{HHC}-1)}\left|\ln \left(d_{u}\right)-\ln \left(d_{v}\right)\right| \\
= & \sum_{u v \in E_{1}(\mathrm{HHC}-1)}(0) \\
& +\sum_{u v \in E_{2}(\mathrm{HHC}-1)}|\ln (2)-\ln (3)| \\
= & \frac{3652105019575333}{562949953421312} .
\end{aligned}
$$

$$
\begin{aligned}
\operatorname{IRLU}(\mathrm{HHC}-1) & =\sum_{u v \in E(\mathrm{HHC}-1)} \frac{\left|\left(d_{u}\right)-\left(d_{v}\right)\right|}{\min \left(d_{u}, d_{v}\right)} \\
& =\sum_{u v \in E_{1}(\mathrm{HHC}-1)}(0)+\sum_{u v \in E_{2}(\mathrm{HHC}-1)} \frac{|(2)-(3)|}{\min (2,3)} \\
& =8 .
\end{aligned}
$$

$$
\begin{aligned}
\operatorname{IRLF}(\mathrm{HHC}-1) & =\sum_{u v \in E(\mathrm{HHC}-1)} \frac{\left|d_{u}-d_{v}\right|}{\sqrt{\left(d_{u} \times d_{v}\right)}} \\
& =\sum_{u v \in E_{1}(\mathrm{HHC}-1)}(0)+\sum_{u v \in E_{2}(\mathrm{HHC}-1)} \frac{|2-3|}{\sqrt{(2 \times 3)}} \\
& =\frac{8 \sqrt{6}}{3} .
\end{aligned}
$$

$$
\begin{aligned}
\operatorname{IRLA}(\mathrm{HHC}-1) & =\sum_{u v \in E(\mathrm{HHC}-1)} 2 \frac{\left|d_{u}-d_{v}\right|}{d_{u}+d_{v}} \\
& =\sum_{u v \in E_{1}(\mathrm{HHC}-1)}(0)+\sum_{u v \in E_{2}(\mathrm{HHC}-1)} 2 \frac{|2-3|}{2+3} \\
& =\frac{32}{5} .
\end{aligned}
$$




$$
\begin{aligned}
\operatorname{IRD} 1(\mathrm{HHC}-1)= & \sum_{u v \in E(\mathrm{HHC}-1)} \ln \left[1+\left|d_{u}-d_{v}\right|\right] \\
= & \sum_{u v \in E_{1}(\mathrm{HHC}-1)}(0) \\
& +\sum_{u v \in E_{2}(\mathrm{HHC}-1)} \ln [1+|(2)-(3)|] \\
= & \frac{6243314768165359}{562949953421312} .
\end{aligned}
$$$$
\operatorname{IRGA}(\mathrm{HHC}-1)=\sum_{u v \in E(\mathrm{HHC}-1)} \ln \left(\frac{d_{u}+d_{v}}{2 \sqrt{\left(d_{u} \times d_{v}\right)}}\right)
$$$$
=\sum_{u v \in E_{1}(\mathrm{HHC}-1)}
$$$$
+\sum_{u v \in E_{2}(\mathrm{HHC}-1)} \ln \left(\frac{2+3}{2 \sqrt{(2 \times 3)}}\right)
$$$$
=\frac{2941534708959071}{9007199254740992} \text {. }
$$

Theorem 4. For the hierarchical hypercube network HHC - 2, we have
(1) $\operatorname{VAR}(H H C-2)=\left(2 a+1 / 4(a+1)^{2}\right)$
(2) $A L(H H C-2)=24$
(3) $\operatorname{IR} 1(H H C-2)=(28(2 a+1) / a+1)$
(4) $\operatorname{IR} 2(H H C-2)=4 \sqrt{2} \sqrt{(16 a+11 / 32 a+28)}$ $-(8 a+7 /(2(a+1)))$
(5) $\operatorname{IRF}(H H C-2)=24$
(6) $\operatorname{IRFW}(H H C-2)=(3 / 64 a+44)$
(7) $\operatorname{IRA}(H H C-2)=(20694009944167803 /$ $144115188075855872)$
(8) $\operatorname{IRB}(H H C-2)=(15520507458125877 /$ 9007199254740992)
(9) $\operatorname{IRC}(H H C-2)=(128 a+48 \sqrt{3}+16 / 32 a+28)-$ $(64 a+56 / 16 a+16)$
(10) $\operatorname{IRDIF}(\mathrm{HHC}-2)=14$
(11) $\operatorname{IRL}(H H C-2)=(3886814622885039 /$ 562949953421312)
(12) $\operatorname{IRLU}(\mathrm{HHC}-2)=8$
(13) $\operatorname{IRLF}(H H C-2)=4 \sqrt{3}$
(14) $\operatorname{IRLA}(H H C-2)=(48 / 7)$
(15) $\operatorname{IRD} 1(\mathrm{HHC}-2)=(18729944304496077 /$ 1125899906842624)
(16) $\operatorname{IRGA}(H H C-2)=(2228664339909267 /$ 9007199254740992)

Proof. The order of graph is $n=|V(\mathrm{HHC}-2)|=16 a+16$, and its size is $m=|E(\mathrm{HHC}-2)|=32 a+28$. The vertex set of $\mathrm{HHC}-2$ can be divided into the following classes by means of degrees:

$$
\begin{aligned}
& V_{1}(\mathrm{HHC}-2)=\left\{v \in V(\mathrm{HHC}-2): d_{u}=3\right\}, \\
& V_{2}(\mathrm{HHC}-2)=\left\{v \in V(\mathrm{HHC}-2): d_{u}=4\right\} .
\end{aligned}
$$

The edge set of $\mathrm{HHC}-2$ can be divided into the following classes with respect to the degrees of end vertices:

$$
\begin{aligned}
& E_{1}(\mathrm{HHC}-2)=\left\{u v \in E(\mathrm{HHC}-2): d_{u}=d_{v}=4\right\}, \\
& E_{2}(\mathrm{HHC}-2)=\left\{u v \in E(\mathrm{HHC}-2): d_{u}=3, d_{v}=4\right\} .
\end{aligned}
$$

And the cardinality of edges is as follows:

$$
\begin{aligned}
& \left|E_{1}(\mathrm{HHC}-2)\right|=32 a+4, \\
& \left|E_{2}(\mathrm{HHC}-2)\right|=24 .
\end{aligned}
$$

First, we find some topological indices, which will be used in irregularity indices:

$$
\begin{aligned}
M_{1}(H H C-2) & =256 a+200, \\
M 2(H H C-2) & =512 a+352, \\
F(H H C-2) & =1024 a+728, \\
\text { RR }(H H C-2) & =128 a+48 \sqrt{3}+16 .
\end{aligned}
$$

Now, from definitions, we have

$$
\begin{aligned}
\operatorname{VAR}(\mathrm{HHC}-2) & =\frac{M_{1}(\mathrm{HHC}-2)}{n}-\left(\frac{2 m}{n}\right)^{2} \\
& =\frac{256 a+200}{16 a+16}-\left(\frac{232 a+28}{16 a+16}\right)^{2} \\
& =\frac{2 a+1}{4(a+1)^{2}} . \\
\operatorname{AL}(\mathrm{HHC}-2) & =\sum_{u v \in E(\mathrm{HHC}-2)}\left|d_{u}-d_{v}\right| \\
& =\sum_{u v \in E_{1}(\mathrm{HHC}-2)}(0)+\sum_{u v \in E_{2}(\mathrm{HHC}-2)}|(3)-(4)| \\
& =24 .
\end{aligned}
$$

$$
\begin{aligned}
\operatorname{IR} 1(\mathrm{HHC}-2) & =F(\mathrm{HHC}-2)-\frac{2 m}{n} M_{1}(\mathrm{HHC}-2) \\
& =1024 a+728-\frac{2(32 a+28)}{16 a+16} 256 a+200 \\
& =\frac{28(2 a+1)}{a+1} .
\end{aligned}
$$

$$
\begin{aligned}
\operatorname{IR} 2(\mathrm{HHC}-2) & =\sqrt{\frac{M_{2}(\mathrm{HHC}-2)}{m}}-\frac{2 m}{n} \\
& =\sqrt{\frac{512 a+352}{32 a+28}}-\frac{2(32 a+28)}{16 a+16} \\
& =4 \sqrt{2} \sqrt{\frac{16 a+11}{32 a+28}}-\frac{8 a+7}{2(a+1)}
\end{aligned}
$$




$$
\begin{aligned}
\operatorname{IRF}(\mathrm{HHC}-2) & =F(\mathrm{HHC}-2)-2 M_{2}(\mathrm{HHC}-2) \\
& =1024 a+728-2(512 a+352) \\
& =24 . \\
\operatorname{IRFW}(\mathrm{HHC}-2) & =\frac{\operatorname{IRF}(\mathrm{HHC}-2)}{M_{2}(\mathrm{HHC}-2)} \\
& =\frac{24}{512 a+352} \\
& =24 .
\end{aligned}
$$

$$
\begin{aligned}
\operatorname{IRA}(\mathrm{HHC}-2)= & \sum_{u v \in E(\mathrm{HHC}-2)}\left(d_{u}^{-1 / 2}-d_{v}^{-1 / 2}\right)^{2} \\
= & \sum_{u v \in E_{1}(\mathrm{HHC}-2)}(0) \\
& +\sum_{u v \in E_{2}(\mathrm{HHC}-2)}\left((3)^{-1 / 2}-(4)^{-1 / 2}\right)^{2} \\
= & \frac{20694009944167803}{144115188075855872} . \\
\operatorname{IRB}(\mathrm{HHC}-2)= & \sum_{u v \in E(\mathrm{HHC}-2)}\left(d_{u}^{1 / 2}-d_{v}^{1 / 2}\right)^{2} \\
= & \sum_{u v \in E_{1}(\mathrm{HHC}-2)}(0) \\
& +\sum_{u v \in E_{2}(\mathrm{HHC}-2)}\left((3)^{1 / 2}-(4)^{1 / 2}\right)^{2} \\
= & \frac{15520507458125877}{9007199254740992} . \\
\operatorname{IRC}(\mathrm{HHC}-2)= & \frac{\mathrm{RR}(\mathrm{HHC}-2)}{m}-\frac{2 m}{n} \\
= & \frac{128 a+48 \sqrt{3}+16}{32 a+28}-\frac{2(32 a+28)}{16 a+16} \\
= & \frac{128 a+48 \sqrt{3}+16}{32 a+28}-\frac{64 a+56}{16 a+16} .
\end{aligned}
$$

$$
\begin{aligned}
\operatorname{IRDIF}(\mathrm{HHC}-2) & =\sum_{u v \in E(\mathrm{HHC}-2)}\left|\frac{d_{u}}{d_{v}}-\frac{d_{v}}{d_{u}}\right| \\
& =\sum_{u v \in E_{1}(\mathrm{HHC}-2)}(0)+\sum_{u v \in E_{2}(\mathrm{HHC}-2)}\left|\frac{3}{4}-\frac{4}{3}\right| \\
& =14 .
\end{aligned}
$$

$$
\begin{aligned}
\operatorname{IRL}(\mathrm{HHC}-2)= & \sum_{u v \in E(\mathrm{HHC}-2)}\left|\ln \left(d_{u}\right)-\ln \left(d_{v}\right)\right| \\
= & \sum_{u v \in E_{1}(\mathrm{HHC}-2)}(0) \\
& +\sum_{u v \in E_{2}(\mathrm{HHC}-2)}|\ln (3)-\ln (4)| \\
= & \frac{3886814622885039}{562949953421312} .
\end{aligned}
$$

$$
\begin{aligned}
\operatorname{IRLU}(\mathrm{HHC}-2) & =\sum_{u v \in E(\mathrm{HHC}-2)} \frac{\left|\left(d_{u}\right)-\left(d_{v}\right)\right|}{\min \left(d_{u}, d_{v}\right)} \\
& =\sum_{u v \in E_{1}(\mathrm{HHC}-2)}(0)+\sum_{u v \in E_{2}(\mathrm{HHC}-2)} \frac{|(3)-(4)|}{\min (3,4)} \\
& =8 .
\end{aligned}
$$

$$
\begin{aligned}
\operatorname{IRLF}(\mathrm{HHC}-2) & =\sum_{u v \in E(\mathrm{HHC}-2)} \frac{\left|d_{u}-d_{v}\right|}{\sqrt{\left(d_{u} \times d_{v}\right)}} \\
& =\sum_{u v \in E_{1}(\mathrm{HHC}-2)}(0)+\sum_{u v \in E_{2}(\mathrm{HHC}-2)} \frac{|3-4|}{\sqrt{(3 \times 4)}} \\
& =4 \sqrt{3} .
\end{aligned}
$$

$$
\begin{aligned}
\operatorname{IRLA}(\mathrm{HHC}-2) & =\sum_{u v \in E(\mathrm{HHC}-2)} 2 \frac{\left|d_{u}-d_{v}\right|}{d_{u}+d_{v}} \\
& =\sum_{u v \in E_{1}(\mathrm{HHC}-2)}(0)+\sum_{u v \in E_{2}(\mathrm{HHC}-2)} 2 \frac{|3-4|}{3+4} \\
& =\frac{48}{7} .
\end{aligned}
$$

$$
\begin{aligned}
\operatorname{IRD} 1(\mathrm{HHC}-2)= & \sum_{u v \in E(\mathrm{HHC}-2)} \ln \left[1+\left|d_{u}-d_{v}\right|\right] \\
= & \sum_{u v \in E_{1}(\mathrm{HHC}-2)}(0) \\
& +\sum_{u v \in E_{2}(\mathrm{HHC}-2)} \ln [1+|(3)-(4)|] \\
= & \frac{18729944304496077}{1125899906842624} . \\
\operatorname{IRGA}(\mathrm{HHC}-2)= & \sum_{u v \in E(\mathrm{HHC}-2)} \ln \left(\frac{d_{u}+d_{v}}{2 \sqrt{\left(d_{u} \times d_{v}\right)}}\right) \\
= & \sum_{u v \in E_{1}(\mathrm{HHC}-2)}(0) \\
& +\sum_{u v \in E_{2}(\mathrm{HHC}-2)} \ln \left(\frac{3+4}{2 \sqrt{(3 \times 4)}}\right) \\
= & \frac{2228664339909267}{9007199254740992} .
\end{aligned}
$$

\section{Conclusion}

In this paper, we have computed several degree-based irregularity indices of block shift networks and hierarchical hypercube networks. Our results are applicable in chemistry, physics, and other applied sciences. Topological indices help us to understand structural properties of understudy 
networks [58-63]. The computed results give understanding about the irregularities of understudy networks.

\section{Data Availability}

The data used to support the findings of this study are included within the article.

\section{Conflicts of Interest}

The authors declare that there are no conflicts of interest regarding the publication of this paper.

\section{Authors' Contributions}

All authors contributed equally to this work.

\section{Acknowledgments}

This paper was supported by the Anhui Natural Science Research Project (2017) under Grant no. KJ2017A469, Scientific Research Project (2018) of Tongling University under Grant no. 2017tlxyzd5, and Top-Notch Talents Cultivation Project of Anhui Higher Education under Grant no. gxgnfx2018044.

\section{References}

[1] J.-B. Liu, C. Wang, S. Wang, and B. Wei, "Zagreb indices and multiplicative zagreb indices of eulerian graphs," Bulletin of the Malaysian Mathematical Sciences Society, vol. 42, no. 1, pp. 67-78, 2019.

[2] M. C. M. Kumar and H. M. Nagesh, "Directed pathos total digraph of an arborescence," Engineering and Applied Science Letters, vol. 1, no. 1, pp. 29-42, 2018.

[3] H. M. Nagesh and M. C. M. Kumar, "Block digraph of a directed graph," Open Journal of Mathematical Sciences, vol. 2, no. 1, pp. 202-208, 2018.

[4] G. V. Rajasekharaiah and U. P. Murthy, "Secure domination in lict graphs," Open Journal of Mathematical Sciences, vol. 2, no. 1, pp. 134-145, 2018.

[5] N. Ali, M. A. Umar, A. Tabassum, and A. Raheem, "Super (a, d)-C3-antimagicness of a corona graph," Open Journal of Mathematical Sciences, vol. 2, no. 1, pp. 371-278, 2018.

[6] J.-B. Liu, X.-F. Pan, F.-T. Hu, and F.-F. Hu, "Asymptotic Laplacian-energy-like invariant of lattices," Applied Mathematics and Computation, vol. 253, pp. 205-214, 2015.

[7] G. Liu, Z. Jia, and W. Gao, "Ontology similarity computing based on stochastic primal dual coordinate technique," Open Journal of Mathematical Sciences, vol. 2, no. 1, pp. 221-227, 2018.

[8] J.-B. Liu and X.-F. Pan, "Minimizing Kirchhoff index among graphs with a given vertex bipartiteness," Applied Mathematics and Computation, vol. 291, pp. 84-88, 2016.

[9] J. B. Liu, J. Zhao, and Z. Zhu, "On the number of spanning trees and normalized Laplacian of linear octagonal-quadrilateral networks," International Journal of Quantum Chemistry, vol. 59, Article ID e25971, 2019.

[10] L. N. Bhuyan, Q. Yang, and D. P. Agrawal, "Performance of multiprocessor interconnection networks," Computer, vol. 22, no. 2, pp. 25-37, 1989.

[11] T.-Y Feng, "A survey of interconnection networks," Computer, vol. 14, no. 12, pp. 12-27, 1981.
[12] J. M. Kumar and L. M. Patnaik, "Extended hypercube: a hierarchical interconnection network of hypercubes," IEEE Transactions on Parallel and Distributed Systems, vol. 3, no. 1, pp. 45-57, 1992.

[13] K. Ghose and K. R. Desai, "Hierarchical cubic networks," IEEE Transactions on Parallel and Distributed Systems, vol. 6, no. 4, pp. 427-435, 1995.

[14] S. Konstantinidou, "The selective extra stage buttery," IEEE Transactions on Very Large Scale Integration (VLSI) Systems, vol. 1, Article ID 502506, 1992.

[15] M. A. Umar, M. A. Javed, M. Hussain, and B. R. Ali, "Super (a, d)-C4-antimagicness of book graphs," Open Journal of Mathematical Sciences, vol. 2, no. 1, pp. 115-121, 2018.

[16] Z. Tang, L. Liang, and W. Gao, "Wiener polarity index of quasi-tree molecular structures," Open Journal of Mathematical Sciences, vol. 2, no. 1, pp. 73-83, 2018.

[17] M. S. Sardar, S. Zafar, and M. R. Farahani, "The generalized zagreb index of capra-designed planar benzenoid series $\$ \mathrm{Ca} \_\mathrm{k}$ (C_6)\$," Open Journal of Mathematical Sciences, vol. 1, no. 1, pp. 44-51, 2017.

[18] S. Noreen and A. Mahmood, "Zagreb polynomials and redefined zagreb indices for the line graph of carbon nanocones," Open Journal of Mathematical Analysis, vol. 2, no. 1, pp. 66-73, 2018.

[19] M. S. Anjum and M. U. Safdar, " $K$ Banhatti and $K$ hyperBanhatti indices of nanotubes," Engineering and Applied Science Letters, vol. 2, no. 1, pp. 19-37, 2019.

[20] G. Chartrand, P. Erdös, and O. R. Oellermann, "How to define an irregular graph," The College Mathematics Journal, vol. 19, no. 1, pp. 36-42, 1988.

[21] M. Behzad and G. Chartrand, "No graph is perfect," The American Mathematical Monthly, vol. 74, no. 8, pp. 962-963, 1967.

[22] B. Horoldagva, L. Buyantogtokh, S. Dorjsembe, and I. Gutman, "Maximum size of maximally irregular graphs," MATCH Communications in Mathematical and in Computer Chemistry, vol. 76, pp. 81-98, 2016.

[23] F. Liu, Z. Zhang, and J. Meng, "The size of maximally irregular graphs and maximally irregular triangle-free graphs," Graphs and Combinatorics, vol. 30, no. 3, pp. 699-705, 2014.

[24] L. Von Collatz and S. Ulrich, "Spektren endlicher grafen," In Abhandlungen aus dem Mathematischen Seminar der Universitat Hamburg, vol. 21, no. 1, pp. 63-77, 1957.

[25] F. K. Bell, "A note on the irregularity of graphs," Linear Algebra and Its Applications, vol. 161, pp. 45-54, 1992.

[26] M. O. Albertson, "The irregularity of a graph," Ars Combinatoria, vol. 46, pp. 219-225, 1997.

[27] D. Vukičević and A. Graovac, "Valence connectivity versus Randić, Zagreb and modified Zagreb index: a linear algorithm to check discriminative properties of indices in acyclic molecular graphs," Croatica Chemica Acta, vol. 77, no. 3, pp. 501-508, 2004.

[28] H. Abdo and D. Dimitrov, "The total irregularity of graphs under graph operations," Miskolc Mathematical Notes, vol. 15, no. 1, pp. 3-17, 2014.

[29] H. Abdo and D. Dimitrov, "The irregularity of graphs under graph operations," Discussiones Mathematicae Graph Theory, vol. 34, no. 2, pp. 263-278, 2014.

[30] I. Gutman, "Topological indices and irregularity measures," John Bull, vol. 8, pp. 469-475, 2018.

[31] Z. Shao, A. R. Virk, M. S. Javed, M. A. Rehman, and M. R. Farahani, "Degree based graph invariants for the molecular graph of Bismuth Tri-Iodide," Engineering and Applied Science Letters, vol. 2, no. 1, pp. 01-11, 2019. 
[32] A. u. R. Virk, M. N. Jhangeer, and M. A. Rehman, "Reverse zagreb and reverse hyper-zagreb indices for silicon carbide $\backslash\left(S_{-} \_\{2\} C_{-}\{3\} \mathrm{I}[\mathrm{r}, \mathrm{s}] \backslash\right)$ and $\backslash\left(\mathrm{Si}_{-}\{2\} \mathrm{C}_{-}\{3\} \mathrm{II}[\mathrm{r}, \mathrm{s}] \backslash\right)$," Engineering and Applied Science Letters, vol. 1, no. 2, pp. 37-50, 2018.

[33] N. De, "Computing reformulated first zagreb index of some chemical graphs as an application of generalized hierarchical product of graphs," Open Journal of Mathematical Sciences, vol. 2, no. 1, pp. 338-350, 2018.

[34] L. Yan, M. R. Farahani, and W. Gao, "Distance-based indices computation of symmetry molecular structures," Open Journal of Mathematical Sciences, vol. 2, no. 1, pp. 323-337, 2018.

[35] W. Gao, A. Asghar, and W. Nazeer, "Computing degree-based topological indices of jahangir graph," Engineering and Applied Science Letters, vol. 1, no. 1, pp. 16-22, 2018.

[36] M. Riaz, W. Gao, and A. Qudair Baig, "M-polynomials and degree-based topological indices of some families of convex polytopes," Open Journal of Mathematical Sciences, vol. 2, no. 1, pp. 18-28, 2018.

[37] W. Gao, B. Muzaffar, and W. Nazeer, " $K$-Banhatti and $K$ hyper Banhatti indices of dominating David Derived network," Open Journal of Mathematical Analysis, vol. 1, no. 1, pp. 13-24, 2017.

[38] H. Siddiqui and M. R. Farahani, "Forgotten polynomial and forgotten index of certain interconnection networks," Open Journal of Mathematical Analysis, vol. 1, no. 1, pp. 44-59, 2017.

[39] M. S. Sardar and X.-F. Pan, "Computing sanskruti index of titania nanotubes," Open Journal of Mathematical Sciences, vol. 1, no. 1, pp. 126-131, 2017.

[40] H. M. U. Rehman, R. Sardar, and A. Raza, "Computing topological indices of Hex Board and its line graph," Open Journal of Mathematical Sciences, vol. 1, no. 1, pp. 62-71, 2017.

[41] M. Munir, W. Nazeer, S. Rafique, and S. Kang, " $M$-polynomial and related topological indices of Nanostar dendrimers," Symmetry, vol. 8, no. 9, p. 97, 2016.

[42] M. Ajmal, W. Nazeer, M. Munir, S. M. Kang, and Y. C. Kwun, "Some algebraic polynomials and topological indices of generalized prism and toroidal polyhex networks," Symmetry, vol. 9, no. 1, p. 5, 2017.

[43] Z. Iqbal, A. Aslam, M. Ishaq, and M. Aamir, "Characteristic study of irregularity measures of some nanotubes," Canadian Journal of Physics, vol. 97, 2019.

[44] W. Gao, M. Aamir, Z. Iqbal, M. Ishaq, and A. Aslam, "On irregularity measures of some dendrimers structures," Mathematics, vol. 7, no. 3, p. 271, 2019.

[45] H. Abdo, D. Dimitrov, and W. Gao, "On the irregularity of some molecular structures," Canadian Journal of Chemistry, vol. 95, no. 2, pp. 174-183, 2016.

[46] Z. Hussain, S. Rafique, and M. Munir, "Irregularity molecular descriptors of hourglass, jagged-rectangle, and triangular benzenoid systems," Processes, vol. 7, no. 7, p. 413, 2019.

[47] W. Gao, M. Asif, and W. Nazeer, "The study of honey comb derived network via topological indices," Open Journal of Mathematical Analysis, vol. 2, no. 2, pp. 10-26, 2018.

[48] R. Kanabu and S. Hosamani, "Some numerical invariants associated with $V$-phenylenic nanotube and nanotori," Engineering and Applied Science Letters, vol. 1, no. 1, pp. 1-9, 2018.

[49] N. De, "Hyper zagreb index of bridge and chain graphs," Open Journal of Mathematical Sciences, vol. 2, no. 1, pp. 1-17, 2018.

[50] M. Imran, A. Asghar, and A. Q. Baig, "On graph invariants of oxide network," Engineering and Applied Science Letters, vol. 1, no. 1, pp. 23-28, 2018.
[51] A. Ali, W. Nazeer, M. Munir, and S. M. Kang, "M-polynomials and topological indices of zigzag and rhombic benzenoid systems," Open Chemistry, vol. 16, no. 1, pp. 73-78, 2018.

[52] S. M. Kang, M. A. Zahid, A. U. R. Virk, W. Nazeer, and W. Gao, "Calculating the degree-based topological indices of dendrimers," Open Chemistry, vol. 16, no. 1, pp. 681-688, 2018.

[53] Y. Pan, The Block Shift Network: Interconnection Strategies for Large Parallel Systems, University of Pittsburgh, Pittsburgh, PA, USA, 1992.

[54] Y. Pan and H. Y. H. Chuang, "Properties and performance of the block shift network," IEEE Transactions on Circuits and Systems I: Fundamental Theory and Applications, vol. 44, no. 2, pp. 93-102, 1997.

[55] Q. M. Malluhi and M. A. Bayoumi, "The hierarchical hypercube: a new interconnection topology for massively parallel systems," IEEE Transactions on Parallel and Distributed Systems, vol. 5, no. 1, pp. 17-30, 1994.

[56] R.-Y. Wu, G.-H. Chen, Y.-L. Kuo, and G. J. Chang, "Nodedisjoint paths in hierarchical hypercube networks," Information Sciences, vol. 177, no. 19, pp. 4200-4207, 2007.

[57] F. P. Preparata and J. Vuillemin, "The cube-connected cycles: a versatile network for parallel computation," Communications of the ACM, vol. 24, no. 5, pp. 300-309, 1981.

[58] W. Gao, M. Younas, A. Farooq, A. Virk, and W. Nazeer, "Some reverse degree-based topological indices and polynomials of dendrimers," Mathematics, vol. 6, no. 10, p. 214, 2018.

[59] S. M. Kang, W. Nazeer, M. A. Zahid, A. R. Nizami, A. Aslam, and M. Munir, "M-polynomials and topological indices of hex-derived networks," Open Physics, vol. 16, no. 1, pp. 394-403, 2018.

[60] W. Gao, M. Younas, A. Farooq, A. Mahboob, and W. Nazeer, " $M$-polynomials and degree-based topological indices of the crystallographic structure of molecules," Biomolecules, vol. 8, no. 4, p. 107, 2018.

[61] W. Gao, M. K. Jamil, W. Nazeer, and M. Amin, "Degree-based multiplicative atom-bond connectivity index of nanostructures," International Journal of Applied Mathematics, vol. 47, no. 4, 2017.

[62] M. S. Ahmad, W. Nazeer, S. M. Kang, M. Imran, and W. Gao, "Calculating degree-based topological indices of dominating David derived networks," Open Physics, vol. 15, no. 1, pp. 1015-1021, 2017.

[63] Y. Kwun, A. Virk, W. Nazeer, M. Rehman, and S. Kang, "On the multiplicative degree-based topological indices of siliconcarbon Si2C3-I[p, q] and Si2C3-II[p, q]," Symmetry, vol. 10, no. 8, p. 320, 2018. 

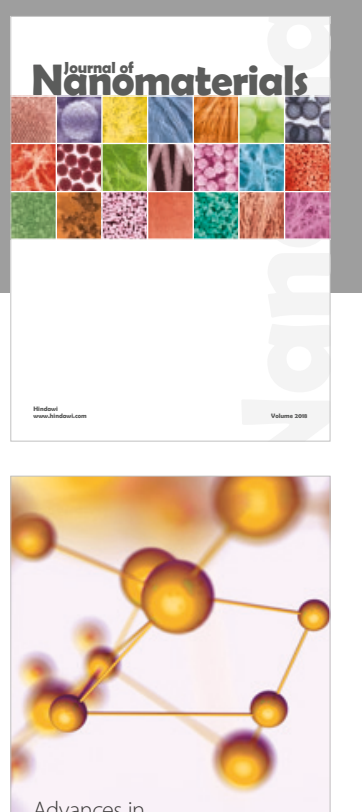

Physical Chemistry
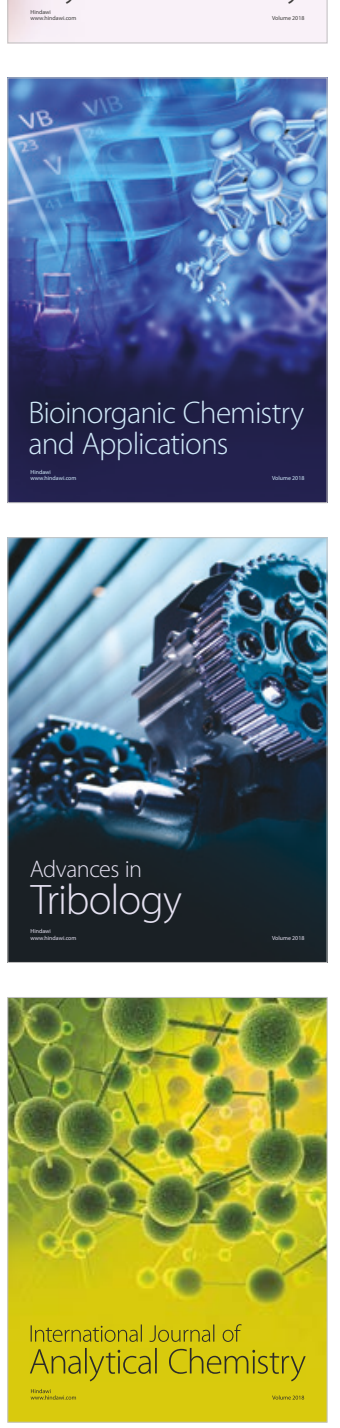

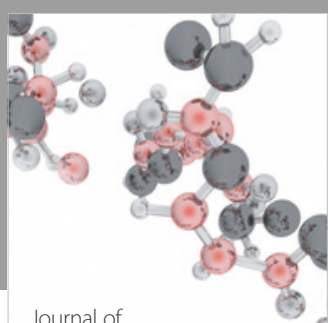

Analytical Methods

in Chemistry

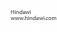

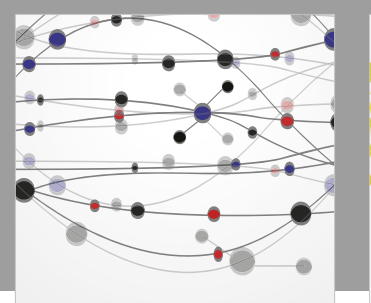

The Scientific World Journal

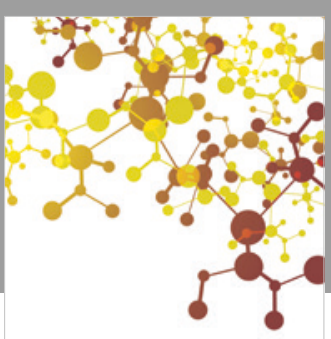

Journal of

Applied Chemistry
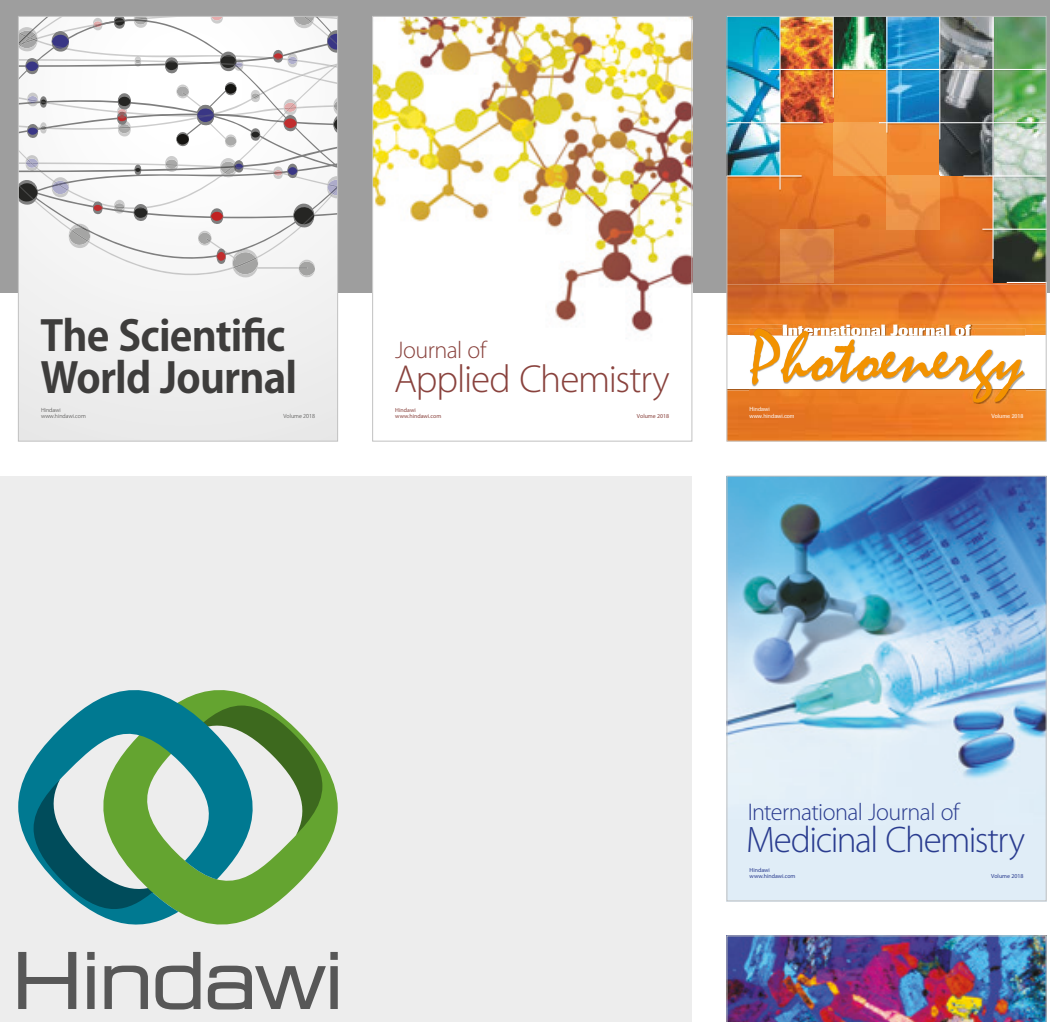

Submit your manuscripts at

www.hindawi.com
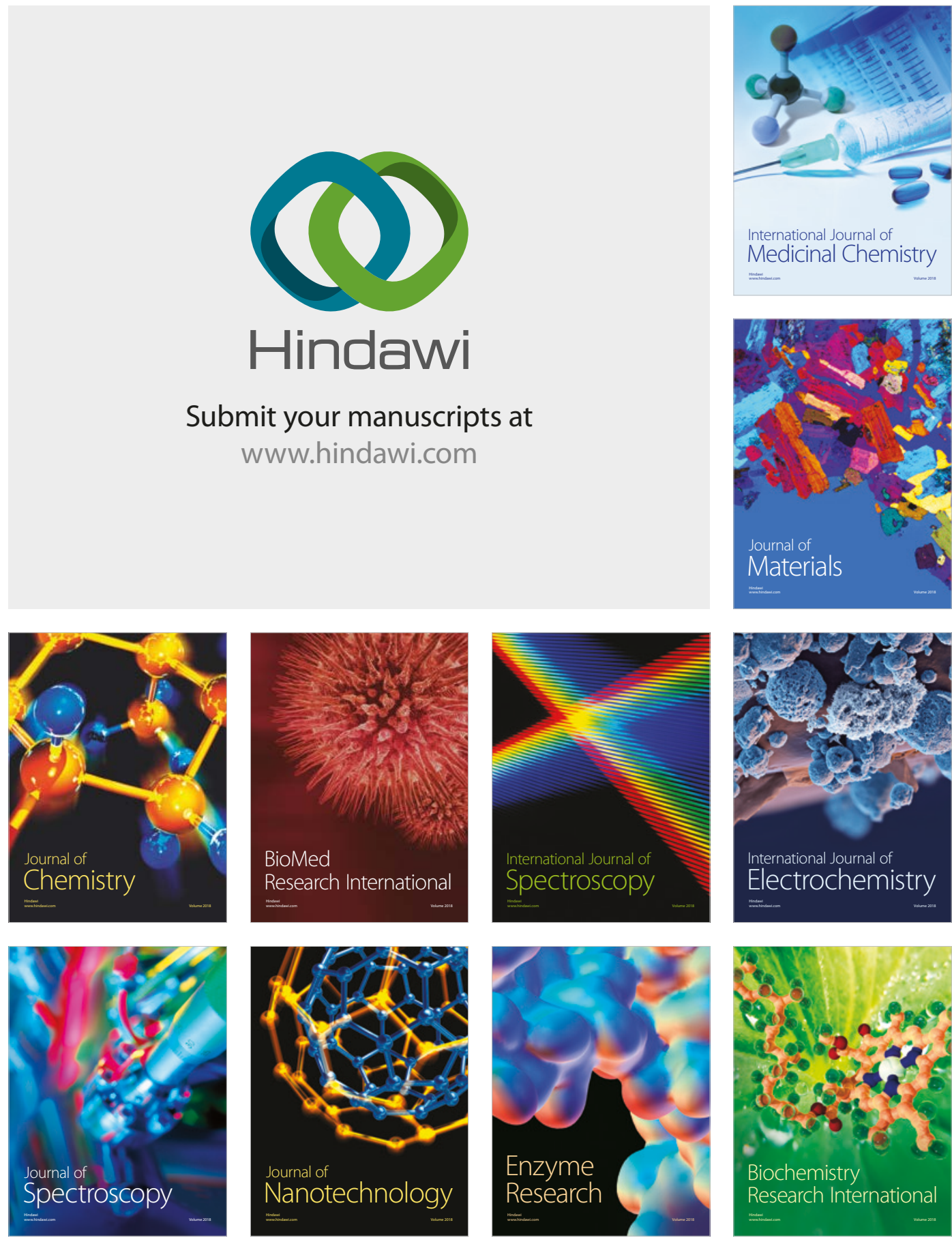
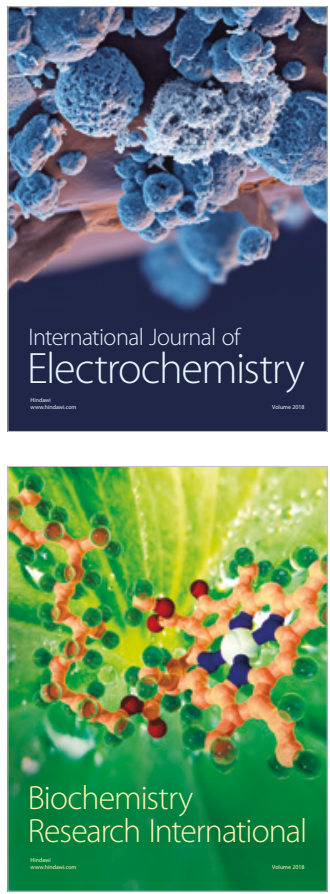